\title{
DUPLA CARREIRA PARA ESTUDANTES- ATLETAS DO TURFE: entendendo a dedicação à escola e ao esporte ${ }^{1}$
}

Hugo Paula Almeida da Rocha

Colégio Pedro II - CPII

Felipe Rodrigues da Costa

Universidade de Brasília - UnB

Antonio Jorge Gonçalves Soares

Universidade Federal do Rio de Janeiro - UFRJ

\begin{abstract}
Resumo
O objetivo do artigo é entender como os estudantes-atletas de turfe administram as rotinas de treinamento e competições desse esporte com as horas destinadas à escolarização. O grupo investigado foi composto por 11 estudantes-atletas, em idade escolar, que administram a dupla carreira escolar e esportiva. Foram aplicados questionários e entrevistas para captar as rotinas escolares e esportivas dos estudantes-atletas, bem como suas expectativas escolares e profissionais quanto à carreira de jóquei. Os dados apontaram que os estudantes-atletas, apesar da alta carga de trabalho físico, permanecem, com dificuldades, na escola. Tal permanência se dá na medida em que as escolas adotam informalmente medidas de flexibilização das normas em relação à frequência, aos horários e aos períodos de avaliação. Esses acordos entre estudantes-atletas, dirigentes do turfe e responsáveis facilitam a permanência dos jovens na escola, porém, não garantem a dedicação e imersão necessárias à incorporação de capital cultural.
\end{abstract}

Palavras-chave: Educação; Dupla Carreira; Esporte; Turfe.

\begin{abstract}
The aim of this research was to understand how the student-athletes of turf manage the training routines and competitions of this sport with the time spent in school. The investigated group consisted of 11 school-aged jockeys who managed a dual career in school and sport. We used questionnaires and conducted interviews with these athletes to collect data. We talked about daily routine and athlete's expectations in school and sport career. The research showed that athlete's physical exercise routine is hard and they stayed in school with difficulties. This permanence occurs because the school adopt informally measures to make your rules more flexible, as regarding the frequency, timetable and conditions for evaluation. These agreements among students, their parents and jockey managers facilitate the permanence of athletes in school, but do not guarantee the dedication and immersion required to incorporate cultural capital.
\end{abstract}

Keywords: Education; Dual Career; Sport; Turf.

ISSN 1645-1384 (online) www.curriculosemfronteiras.org 


\section{Introdução}

O estudo em tela tomou o processo de formação esportiva no turfe ${ }^{2}$ como um objeto privilegiado para entender a dupla carreira, na medida em que essa modalidade recruta jovens das camadas populares e oferece um rápido retorno financeiro ainda na fase de formação esportiva. Além disso, o turfe, mesmo sendo classificado como modalidade esportiva, não é representado socialmente dessa forma e possui uma certa invisibilidade no mercado dos esportes atualmente. São as apostas financeiras que motivam as competições esportivas no turfe, e, mesmo assim, essa é uma atividade que perdeu glamour e status se comparada ao seu apogeu, na virada do século XIX para o século XX (Melo, 2001). Todavia, uma pequena parte de jovens, geralmente do meio rural, é selecionada para esse tipo de atividade.

A seleção para a categoria de formação para o turfe acontece quando o indivíduo completa 16 anos de idade. A definição dessa faixa etária ocorre porque, de acordo com o Estatuto da Criança e do Adolescente (ECA) e com a Consolidação das Leis do Trabalho (CLT), um contrato profissional só pode ser assinado por menores quando esses completam 16 anos de idade (Brasil, 1943, 1990).

Observa-se que o cuidado que se tem para selecionar jovens aptos a assinarem um contrato profissional como atleta é um reconhecimento de que essa modalidade esportiva é um campo de trabalho e, portanto, os jovens contratados podem vir a ser encarados como trabalhadores do esporte. A figura jurídica do atleta em formação como trabalhador do esporte, quando se trata de menor de idade, ainda é incipiente na legislação brasileira e carente de regulamentação, tornando a interpretação dessa figura jurídica dependente da exegese do ECA e da CLT (Rocha, 2017; Rocha et al, 2020).

No cenário nacional, os estudos realizados sobre dupla carreira tomam, em geral, esportes que possuem grande popularidade e apelo midiático no mercado (Melo et al., 2016; Correia, 2014; Melo, Soares, Rocha, 2014; Rocha et al., 2011; Melo, 2010). A caracterização do processo de ingresso e permanência na profissionalização no turfe contribui para que compreendamos a complexidade do contexto de escolhas para a dedicação simultânea ao esporte e à escola com base em uma modalidade esportiva singular e quase invisível atualmente no mercado dos esportes profissionais.

O dilema da dupla carreira se dá em função da harmonização entre as rotinas obrigatórias no esporte e na educação, por essa razão, quando o jovem decide se empenhar na carreira esportiva, em geral, acaba por ter prejuízos nas atividades comuns da vida social (Epiphanio, 2002; Paoli, 2007; Soares et al., 2013; Melo, Soares, Rocha, 2014; Rocha, 2017). As pesquisas sobre dupla carreira destacam que os estudantes-atletas têm dificuldades quanto à organização das rotinas e obrigações do dia a dia. Estudos nacionais apontam que os obstáculos enfrentados na rotina de dupla carreira estão associados ao cansaço físico e às pressões internas causadas pela intensa seletividade e competitividade no esporte (Melo, 2010; Costa, 2012; Rocha, 2013, 2017; Correia, 2014; Costa e Silva, 2016; Romão, 2017).

As pesquisas internacionais sugerem que a compatibilização da dupla carreira somente é possível quando se criam estratégias de conciliação entre as demandas de treinamentos e competições e as demandas escolares. Tais estratégias levam em consideração eixos como: 
(a) a articulação — nos ambientes do esporte, da educação acadêmica e das famílias dos estudantes-atletas - de uma rede de apoio que compreenda os efeitos da dupla carreira esportiva; (b) a conciliação entre as rotinas, com a criação de centros esportivos próximos às instituições educacionais, mitigando o tempo de deslocamento entre as atividades; e (c) a elaboração de políticas públicas e institucionais que reconheçam o estudante-atleta e as dificuldades de conciliar a dupla carreira, no sentido de buscar mecanismos compensatórios para os possíveis prejuízos que essa condição possa vir a causar (Blodgett; Schinke, 2015; Chroni; Diakaki; Papaioannou, 2013; Metsä-Tokila, 2002; Tshube; Feltz, 2015; Guidotti; Cortis; Capranica, 2015).

A literatura indica que o fenômeno social da dupla carreira atinge uma parcela da população juvenil que busca um projeto de profissionalização no esporte no mesmo período da vida que deve cumprir obrigações vinculadas à escolarização e/ou ao trabalho ordinário. No caso dos estudantes-atletas do turfe, poderemos observar o peso que o processo de formação esportiva possui quando comparado com as demandas escolares, pois a formação no turfe coloca seus atletas, desde cedo, diante de uma relação profissional em que cada vitória será remunerada. Assim, a profissionalização apresenta continuidade e se confunde com o processo de formação esportiva. Diante do quadro descrito, o objetivo do artigo é entender como os estudantes-atletas de turfe administram as rotinas de treinamento e competições desse esporte com as horas destinadas à escolarização. Para além de outras dimensões presentes nas estratégias de conciliação da dupla carreira, teremos como foco como são administrados o tempo de permanência na escola ${ }^{3}$ e o tempo dedicado aos treinamentos na modalidade esportiva.

\section{Metodologia}

A população selecionada de estudantes-atletas em formação profissional no turfe, no momento da pesquisa, era de 13 pessoas com idades entre 15 e 18 anos. Todavia, utilizamos como critério de exclusão a residência em local distinto do alojamento do clube onde a pesquisa foi realizada. Com isso, o grupo investigado foi reduzido a 11 estudantes-atletas. Ressaltamos que o critério foi estabelecido com o entendimento de que, para melhor compreender os efeitos da gestão do tempo da dupla carreira esportiva para esses estudantesatletas, deveríamos selecionar aqueles que tivessem características semelhantes para controle dessa variável. É importante mencionar, também, que o único estudante-atleta com 15 anos estava próximo de completar o $16^{\circ}$ aniversário. 
Tabela 1. Perfil dos Atletas

\begin{tabular}{|c|c|c|}
\hline \multicolumn{3}{|c|}{$\begin{array}{l}\text { Perfil } \\
\text { Atletas }\end{array}$} \\
\hline Sexo & Idade & $\begin{array}{c}\text { Série } \\
\text { Escolar } \\
6^{\circ}\end{array}$ \\
\hline Masculino & 17 & $\begin{array}{r}\text { ano_EF } \\
7^{\circ}\end{array}$ \\
\hline Masculino & 17 & $\begin{array}{r}\text { ano_EF } \\
7^{\circ}\end{array}$ \\
\hline Masculino & 17 & ano_EF \\
\hline Masculino & 16 & $\begin{array}{l}8^{\circ} \text { ano_EF } \\
9^{\circ}\end{array}$ \\
\hline Masculino & 17 & $\begin{array}{r}\text { ano_EF } \\
1^{\text {a }}\end{array}$ \\
\hline Masculino & 17 & $\underset{1^{\mathrm{a}}}{\text { Série_EM }}$ \\
\hline Masculino & 17 & $\underset{1^{\mathrm{a}}}{\text { Série_EM }}$ \\
\hline Masculino & 18 & Série_EM \\
\hline Masculino & 17 & $\underset{3^{\mathrm{a}}}{\text { Série_EM }}$ \\
\hline Masculino & 17 & Série_EM \\
\hline Masculino & 17 & Série_EM \\
\hline
\end{tabular}

Fonte: Trabalho de campo

De acordo com os dados da pesquisa, observamos que a renda familiar desses atletas, em valores atuais, girava entre $R \$ 719,81$ e $R \$ 3.085,48$, o que classificaria essas famílias como pertencentes às classes $\mathrm{C}, \mathrm{D}$ e E. A base de cálculo utilizada para tal estimativa foi a partir do Critério de Classificação Econômica Brasil, desenvolvido pela Associação Brasileira de Empresas de Pesquisa (ABEP, 2019).

Consideramos ainda a escolaridade dos pais dos atletas, que organizamos na tabela a seguir: 
Tabela 2. Escolaridade dos Pais

\begin{tabular}{ccc}
\hline & Escolaridade dos pais & \\
\hline Série/ano & Frequência_Mãe & Frequência_Pai \\
$4^{\mathrm{a}} / 5^{\circ}$ do Ensino Fundamental & 1 & 1 \\
$5^{\mathrm{a} / 6^{\circ}}$ do Ensino Fundamental & 2 & 3 \\
$6^{\mathrm{a}} / 7^{\mathbf{o}}$ do Ensino Fundamental & 1 & 0 \\
$7^{\mathrm{a}} / 8^{\mathbf{o}}$ do Ensino Fundamental & 0 & 0 \\
$8^{\mathrm{a}} / 9^{\circ}$ do Ensino Fundamental & 1 & 4 \\
$1^{\mathrm{a}}$ Série do Ensino Médio & 2 & 0 \\
$2^{\mathrm{a}}$ Série do Ensino Médio & 0 & 0 \\
$3^{\mathrm{a}}$ Série do Ensino Médio & 3 & 1 \\
Ensino Superior Incompleto & 0 & 1 \\
Ensino Superior Completo & 1 & 0 \\
Não Sabe & 0 & 1 \\
Total & 11 & 11 \\
\hline
\end{tabular}

Fonte: Trabalho de campo

Utilizamos como instrumento de coleta de dados um questionário estruturado, preenchido pelos avaliadores em formulário próprio. Os dados analisados para este artigo referem-se à jornada e à rotina escolar e de treinamento. Realizamos também uma série de entrevistas, nas dependências do próprio clube ${ }^{4}$, com guia semiestruturado, das quais retiramos depoimentos dos atletas para compor os argumentos levantados no decorrer do estudo. Essas entrevistas foram transcritas e analisadas de acordo com categorias definidas - como frequência, jornada escolar e esportiva, tempo de permanência na escola e outras , por meio de comparação e cruzamento dos dados conforme os objetivos da pesquisa.

Utilizamos o termo de consentimento livre e esclarecido e asseguramos aos atletas que suas identidades não seriam expostas em futuras publicações e apresentações públicas da pesquisa (Parecer n ${ }^{\circ}$ 131/2010, aprovado pelo Comitê de Ética da Universidade Gama Filho).

\section{Análise dos dados}

Para a análise do tempo dedicado à escola, utilizamos a referência de Marcelo Neri (2009b), que, em sua pesquisa intitulada "Tempo de permanência na escola", elaborou uma metodologia apurada para tentar aproximar da realidade o quanto um indivíduo se dedicava à instituição escolar. O autor justificou que "a extensão da jornada escolar é uma das poucas variáveis sob o controle dos gestores da política escolar com impacto significativo sobre o desempenho dos alunos" (Neri, 2009b, p. 16). 


\section{Indicadores: Índice de Permanência na Escola}

Neri (2009b) construiu o Índice de Permanência na Escola (IPE) baseando-se nos seguintes indicadores: (a) Índice de Matrícula Escolar (IM); (b) Índice de Frequência Escolar (IF); e (c) Índice de Jornada Escolar (IJ). O autor explicou que esses indicadores foram estabelecidos com base na análise direta dos dados da Pesquisa Nacional por Amostra de Domicílios (PNAD) de 2006.

O Índice de Matrícula Escolar (IM) representa o inverso da taxa de evasão escolar, enquanto o Índice de Frequência Escolar mede a proporção de dias frequentados pelos alunos regularmente matriculados em uma escola. De acordo com Neri (2009b),

O Índice de Jornada Escolar (IJ) nos fornece a extensão das horas diárias dedicadas às aulas vis-à-vis a uma jornada de referência, considerada mínima ideal. Esta é uma variável de oferta decidida pelos gestores educacionais. A Jornada de Referência (JR) aqui considerada é de cinco horas diárias (p. 21, grifo do autor).

Portanto, para se calcular o Índice de Permanência na Escola (IPE) dos estudantes-atletas do turfe, era preciso saber: (a) quantos deles estavam regularmente matriculados, por meio da razão entre o número de matriculados e a amostra investigada (IM); (b) a razão entre a frequência declarada pelos estudantes-atletas e a quantidade de dias letivos de um período específico (IF); e (c) a razão entre a jornada escolar declarada pelos estudantes-atletas e a jornada de referência (IJ). A multiplicação desses três índices geraria o IPE (Neri, 2009b). Em seguida, o IPE deve ser novamente multiplicado pela jornada de referência, chegando ao valor em horas do tempo de permanência na escola (TPE). A tabela a seguir mostra as equações: 
Tabela 3. Índices e equações para o Tempo de Permanência na Escola

\begin{tabular}{|c|c|c|}
\hline Índices & Equações & Legendas \\
\hline Índice de Matrícula (IM) & $I M=\frac{N M}{U}$ & $\begin{array}{c}\mathrm{IM}=\text { Índice de Matrícula } \\
\mathrm{NM}=\text { Número de } \\
\text { Matriculados } \\
\mathrm{U}=\text { Total da população } \\
\text { investigada }\end{array}$ \\
\hline Índice de Frequência (IF) & $I F=\frac{(D L-N F)}{D L}$ & $\begin{array}{c}\mathrm{IF}=\text { Índice de Frequência } \\
\mathrm{DL}=\text { Número de dias letivos } \\
\mathrm{NF}=\text { Número de Faltas }\end{array}$ \\
\hline Índice de Jornada (IJ) & $I J=\frac{J E}{J R}$ & $\begin{array}{c}\mathrm{IJ}=\text { Índice de Jornada } \\
\mathrm{JE}=\text { Jornada escolar } \\
\text { declarada } \\
\mathrm{JR}=\text { Jornada de Referência }\end{array}$ \\
\hline $\begin{array}{l}\text { Índice de Permanência na Escola } \\
\text { (IPE) }\end{array}$ & $I P E=I M \times I F \times I J$ & $\begin{array}{c}\text { IPE = Índice de Permanência } \\
\text { na Escola } \\
\text { IM = Îndice de Matrícula } \\
\text { IF = Índice de Frequência } \\
\text { IJ = Índice de Jornada }\end{array}$ \\
\hline $\begin{array}{l}\text { Tempo de Permanência na Escola } \\
\text { (TPE) }\end{array}$ & $T P E=I P E \times J R$ & $\begin{array}{c}\text { TPE = Tempo de } \\
\text { Permanência na Escola } \\
\text { IPE = Índice de Permanência } \\
\text { na Escola } \\
\text { JR = Jornada de Referência }\end{array}$ \\
\hline
\end{tabular}

Fonte: Neri (2009b)

\section{Características do esporte e rotina}

O turfe é um esporte que possui processo seletivo bastante rigoroso, e podemos dizer que a rotina de treinamento se inicia antes mesmo das primeiras horas do dia. Vale mencionar que poucos jovens são atraídos pela ideia de profissionalização nessa modalidade esportiva. A seleção de jovens para formação de profissionais na modalidade esportiva em foco segue critérios rigorosos, a saber: idade mínima de 16 anos, peso limitado a $48 \mathrm{~kg}$ e altura limitada a $1,57 \mathrm{~m}$. Com os pré-requisitos de acesso cumpridos, o aluno passa a residir no alojamento do clube, onde se habitua ao programa de treinamentos. De segunda-feira a sábado, em dias ensolarados ou chuvosos, o aprendiz de jóquei vai a campo para treinar (Rocha, 2013).

Os estudantes-atletas do turfe no Rio de Janeiro são divididos em duas categorias: alunos e aprendizes da modalidade. Os alunos participam de um período de treinamento e de adaptação ao cavalo, que dura entre 3 e 18 meses, até terem condições técnicas para competir - quando passam a ser considerados aprendizes. Os aprendizes são divididos em quatro níveis, que são galgados de acordo com o número de páreos vencidos. A primeira dessas 
quatro categorias é a do jóquei-aprendiz, a qual corresponde à $4^{\mathrm{a}}$ categoria. Em seguida, os atletas passam pelas $3^{\mathrm{a}}, 2^{\mathrm{a}}$ e $1^{\mathrm{a}}$ categorias até se tornarem jóqueis profissionais.

$\mathrm{Na}$ fase final da formação, o jovem permanecerá por um período de 7 meses como aprendiz de $2^{\text {a }}$ categoria até conquistar o título de aprendiz de $1^{\text {a }}$ categoria. A certificação como jóquei profissional requer do aprendiz de $1^{\text {a }}$ categoria a soma de 60 vitórias, considerando-se apenas aquelas conquistadas nas duas últimas categorias como aprendiz.

Outro ponto a se destacar é a de que cada corrida disputada pelo jóquei-aprendiz conferirlhe-ia uma quantia equivalente a $\mathrm{R} \$ 40,00$. Em caso de vitória, o estudante-atleta receberia também um valor igual a $10 \%$ da premiação paga ao proprietário do cavalo vencedor. Esse percentual decaia até a quinta posição ocupada no pódio. Considerando que em um final de semana o jóquei-aprendiz poderia concorrer a possibilidade de competir em até 40 corridas, verifica-se que o provento recebido pelo estudante-atleta poderia chegar a valores significativos, por exemplo: em consulta às estatísticas do turfe referentes ao período de 01 de julho de 2020 a 15 de junho de 2021, os prêmios alcançados pelos cinco primeiros competidores variaram entre $\mathrm{R} \$ 929.791,61$ e $\mathrm{R} \$ 1.750 .042,53$. Mesmo assim ainda podemos ver outros competidores superando a marca de $\mathrm{R} \$ 1.000 .000,00$ no mesmo período em destaque $^{5}$ (Jockey Club Brasileiro, 2021).

Observemos que as competições nesse esporte conferem aos jóqueis-aprendizes um prêmio financeiro proporcional à classificação em cada uma das corridas. Esse fato pode proporcionar ao atleta do turfe ganhos financeiros significativos por um tipo de atuação especializada. Dessa forma, pode-se supor que essa condição de atleta em formação sugere uma espécie de trabalho com carência de regulamentação na legislação brasileira ${ }^{6}$ (Rocha, 2017). De fato, a condição de atleta remunerado desde os primeiros meses de formação produz uma certa ambiguidade entre formação e profissionalização. Nesse caso, a escola pode ser representada como um obstáculo ou empecilho ao desenvolvimento no esporte na percepção dos atletas.

Destacamos que, enquanto jóquei aprendiz ou jóquei profissional, o estudante-atleta participa das competições regularmente às sextas-feiras, sábados, domingos e segundasfeiras para atender o calendário do esporte. Consideremos, ainda, que as competições às sextas-feiras e às segundas-feiras acontecem no período da noite, horário em que os estudantes-atletas estão matriculados na escola, pois, em função das demandas do esporte e/ou do atraso escolar eles estudam no ensino noturno. Essa simples característica do calendário do turfe coloca esses estudantes-atletas, quando já estão aptos a participar das competições, no dilema entre escolher a escola ou o turfe nas sextas e segundas-feiras. Essa decisão é tomada quase sempre com a renúncia das obrigações escolares no horário das competições turfísticas, o que afeta ainda mais o cálculo do tempo de permanência na escola desses estudantes-atletas.

A rotina de treinamento acontece independentemente da condição climática e da disposição dos estudantes-atletas. O tempo dedicado a essa atividade é de aproximadamente três horas por dia, podendo chegar a quatro horas, em seis dias por semana. Diante das demandas de treinamento, os estudantes-atletas se veem, ainda, na obrigação de manter um peso compatível com as competições, não podendo ultrapassar os 51 quilogramas, sob o risco 
de serem punidos com a exclusão das competições. A participação nas corridas é imprescindível para a permanência dos estudantes-atletas no turfe, visto que a progressão nas categorias depende fundamentalmente do número de vitórias que conseguem alcançar enquanto estão na condição de aprendizes.

A rotina dos estudantes-atletas se inicia por volta das 5 horas da manhã. Após realizarem a higiene pessoal e arrumarem suas camas, partem para as raias, por vezes até mesmo antes do café da manhã, para as atividades com os cavalos, iniciadas pontualmente às 6 horas. Ao término do treinamento, o cotidiano dos estudantes-atletas é preenchido por outras atividades, como a limpeza da cocheira e do alojamento. Além disso, cada um dos estudantes-atletas é responsável por cuidar de um dos cavalos da escola de jóqueis. No período da tarde, observou-se que a rotina dos estudantes-atletas era preenchida por atividades de livre escolha. Alguns praticavam corrida ao redor da Lagoa Rodrigo de Freitas próxima à escola; outros escolhiam jogar futebol com os amigos; alguns descansavam; e outros ainda buscavam aperfeiçoar as técnicas de montaria nas dependências do alojamento.

\section{Rotina de treinamento e permanência na escola}

A tabela 4 mostra que os estudantes-atletas em questão têm uma jornada escolar diária de 3 horas, 48 minutos e 38 segundos, contra 4 horas, 7 minutos e 27 segundos diários de treinamento ${ }^{7}$. Esse tempo foi calculado por meio da informação declarada pelos estudantesatletas sobre o horário de entrada e saída de cada uma das duas atividades. Percebemos que o tempo dedicado à escola é inferior ao de treinamento e, para além do tempo investido, podemos inferir que, no discurso desses jovens, é a profissionalização esportiva que aparece como a prioridade em suas vidas. 
Tabela 4 - Tempo diário gasto nos treinamentos, na escola e nos deslocamentos para a escola e para o treino.

\begin{tabular}{ccccc}
\hline & Tempo treino & $\begin{array}{c}\text { Deslocamento } \\
\text { treino }\end{array}$ & Tempo escola & $\begin{array}{c}\text { Deslocamento } \\
\text { escola }\end{array}$ \\
\hline Média & $04: 07: 27$ & $00: 10: 45$ & $03: 48: 38$ & $00: 24: 36$ \\
Desvio padrão & $00: 29: 03$ & $00: 11: 50$ & $00: 20: 44$ & $00: 22: 45$ \\
\hline
\end{tabular}

Fonte: Trabalho de campo

Entrevistador: Você acha a escola importante?

Estudante-Atleta 4: É importante, mas tenho preguiça...

Entrevistador: Você gosta de estudar?

Estudante-Atleta 11: Não.

Entrevistador: Por quê?

Estudante-Atleta 11: Ah, é chato.

Entrevistador: E para o futuro, qual sua expectativa?

Estudante-Atleta 6: Ah, ganhar muita corrida, fio.

Entrevistador: Qual é sua expectativa em relação ao esporte?

Estudante-Atleta 9: Expectativa é só ganhar.

Podemos relativizar a resposta de que a escola é "importante", pois esse é um tipo de pergunta que gera respostas socialmente esperadas. Por outro lado, o fato de eles identificarem a escola como "chata" retrata o sentimento - também presente em outras enquetes com jovens - de que a desconexão entre conteúdos escolares e a vida dos alunos gera um tipo de desinteresse intrínseco pela escola (Neri, 2009a; Schwartzman, 2011, 2016).

A jornada escolar e o tempo de treinamento diários são aproximados, todavia, devemos considerar que os treinos acontecem em seis dias na semana e, se somados às competições, totalizam sete dias de atividades esportivas. Em comparação com os cinco dias por semana de atividades regulares da escola, fica evidente que o tempo dedicado ao esporte supera sobremaneira o tempo escolar declarado pelos estudantes-atletas. A dedicação que eles dispensam ao esporte e à escola nos leva a acreditar que o foco na carreira é voltado exclusivamente para o turfe em função de vislumbrarem mais possibilidades de inserção na vida profissional que as oferecidas pelo tipo de escolarização que estão submetidos.

Ressaltamos que, para os estudantes-atletas já aprovados em categorias que permitem a disputa de páreos, a diferença entre o tempo dedicado à escola e ao esporte pode ser considerada mais expressiva se calcularmos o tempo de permanência na escola de acordo com Neri (2009b). Tomamos por base que todos os atletas estavam regularmente matriculados (Índice de Matrícula igual a 1) e que o Índice de Jornada Escolar é igual a $0,7621^{8}$. Segundo declarações dos atletas, as competições os levam a perder dois dias de aula por semana. Assim, temos como Índice de Frequência um valor igual a 0,6. Dessa forma, o Índice de Permanência na Escola é igual a 0,45726 (Tabela 5). 
Tabela 5. Índice de Permanência na Escola

\begin{tabular}{cccc}
\hline Índice de Matrícula & $\begin{array}{c}\text { Índice de Jornada } \\
\text { Escolar }\end{array}$ & Índice de Frequência & $\begin{array}{c}\text { Índice de Permanência } \\
\text { na escola }\end{array}$ \\
\hline $\mathbf{1}$ & 0,7621 & 0,6 & 0,45726 \\
\hline
\end{tabular}

Fonte: Trabalho de campo

Retomando a equação de Neri (2009b) — ou seja: TPE = IPE X JR, sendo a jornada de referência igual a 5 horas —, o Tempo de Permanência na Escola dos estudantes-atletas habilitados a competir no turfe será igual a 2 horas, 17 minutos e 11 segundos. Isso indica uma diferença de aproximadamente 1 hora e 30 minutos em relação à média da jornada escolar declarada pelos estudantes-atletas; e quase 1 hora e 50 minutos de discrepância entre o tempo de permanência na escola e a jornada diária de treinamento.

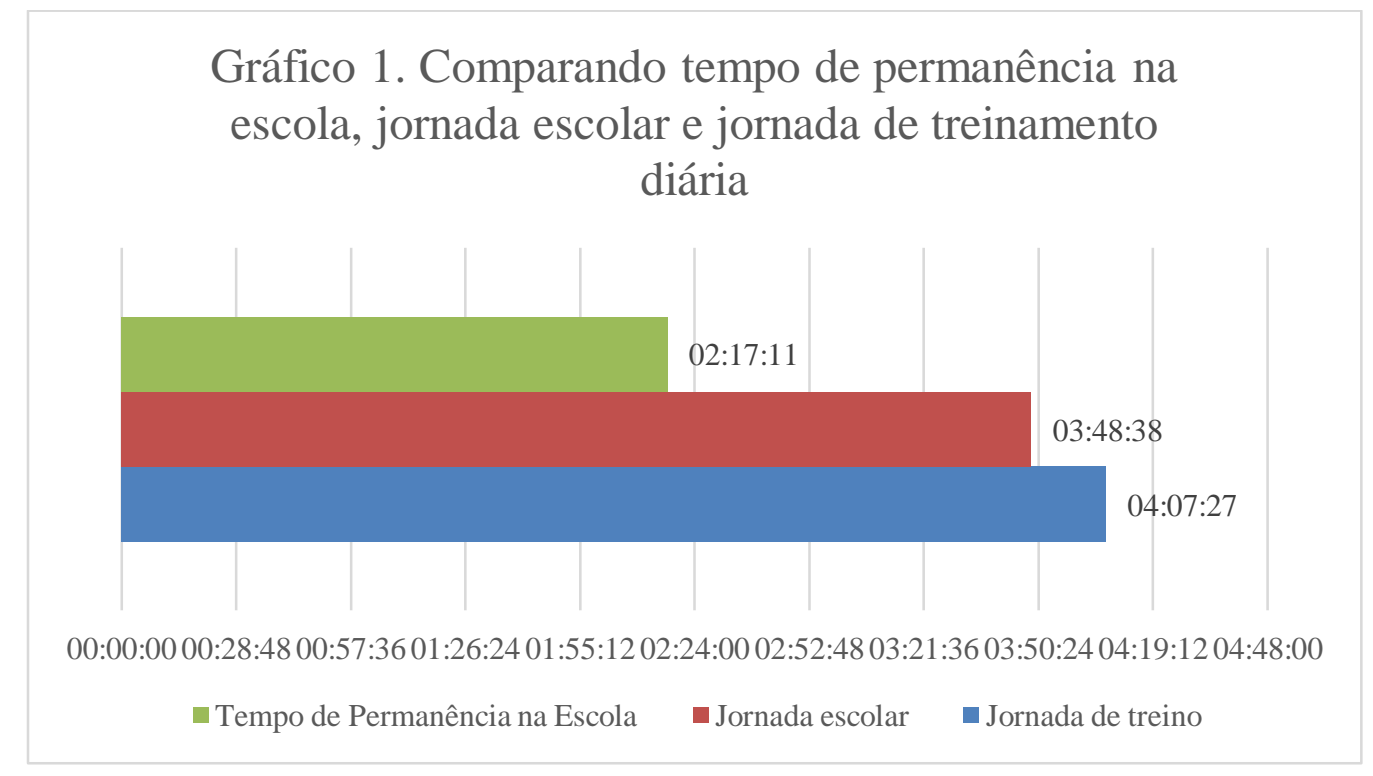

Observemos que o Gráfico 1 demonstra uma diferença significativa do tempo de permanência na escola comparado à jornada escolar e à jornada de treinamento declaradas pelos estudantes-atletas. Pensamos que a maior dedicação ao esporte é traduzida tanto pela quantidade de horas dedicadas à rotina de treinamento quanto pelo investimento nas competições, que os afastam do ambiente escolar em dois dias da semana. Além disso, devemos levar em consideração as percepções subjetivas de sucesso na carreira esportiva e na escolar.

A variável tempo é uma das mais relevantes para se entender a conciliação da dupla carreira do estudante-atleta. Diversas pesquisas trataram sobre o tema em outras modalidades esportivas (Melo, Soares, Rocha, 2014; Melo, 2010; Melo et al., 2016). Quanto ao tipo de tratamento dispensado à variável tempo, verificamos que Rocha et al. (2021) analisou que o tempo de permanência na escola de estudantes-atletas de futebol no Rio de Janeiro também 
é reduzido quando esses migram para o ensino noturno. $\mathrm{O}$ argumento dos autores é o de que a escola noturna possui algum tipo de desestrutura que acaba reduzindo o tempo de dedicação dos estudantes-atletas e dos demais estudantes da escola. Todavia, comparando ao que se observa nos dados para os estudantes-atletas do turfe, considerando que as competições ocorrem em pelo menos dois dias nos horários escolares, isso nos leva a crer que o calendário esportivo atrapalha a vida escolar desse estudante-atleta, para além das críticas que a escola noturna possa receber (Leão, 2018; Krawczyk, 2011; Costa, 2011).

A diferença de padrão entre essa modalidade esportiva e outras, como o futebol, coloca uma dificuldade para o planejamento de políticas públicas generalistas, visto que cada esporte pode criar demandas distintas. Assim, ainda que se sugira uma aproximação entre o centro de treinamento e a escola, junto de uma rede de apoio que inclui as famílias, representantes do clube e agentes escolares, a operacionalização de uma estratégia para intervenção na dupla carreira do estudante-atleta ainda vai carecer da individualização das ações institucionais. Portanto, cada caso deverá ser analisado distintamente.

\section{Atraso escolar dos jóqueis}

Os estudantes-atletas do turfe são obrigados a se matricular na escola, mas a maioria se encontra em situação de atraso escolar. A tabela 1 mostrou a relação entre a idade dos atletas e a série/ano que eles frequentavam. Dos 11 estudantes-atletas analisados, consideramos que apenas três estavam em série compatível com a idade, a saber: um atleta na $2^{\mathrm{a}}$ série do ensino médio e dois na $3^{\mathrm{a}}$ série do ensino médio. Os demais se encontravam com até quatro anos de defasagem na relação idade/ano escolar. Tomemos como exemplo o relato do estudanteatleta 6 , que parou de estudar quando tinha 12 anos e só voltou a se matricular em uma escola porque esta foi uma obrigação imposta pelo clube de turfe, como revelou em sua entrevista:

Entrevistador: Você parou de estudar em que série?

Estudante-Atleta 6: $6^{\circ}$ ano...

Entrevistador: Faz quanto tempo que você está parado?

Estudante-Atleta 6: Ah, desde os 12, só que aqui eu voltei a estudar, mas não fui, comecei e não terminei.

Podemos pressupor que o desinteresse na escola vem em decorrência de uma trajetória acidentada e que a possibilidade de gerar recursos para subsistência através do turfe, independentemente da formação acadêmico/escolar, faz com que esses jovens projetem no esporte uma esperança de inserção profissional e de sobrevivência financeira digna (Rocha, 2013). Destacamos que a imposição do clube sobre a matrícula do atleta é também uma exigência legal, prevista no Estatuto da Criança e do Adolescente (Brasil, 1990), a qual evidencia a responsabilidade de o empregador e/ou o responsável facilitarem as condições de estudos do adolescente trabalhador. 
Se observarmos a configuração do calendário do turfe, veremos que esse afeta o tempo de permanência na escola do estudante-atleta dessa modalidade esportiva. Todavia, não podemos afirmar que este esporte afetaria negativamente as trajetórias escolares de seus atletas. Pois, como vimos, esses atletas já se iniciam no esporte com suas trajetórias escolares acidentadas. Com isso, podemos sugerir que o desinvestimento na escola pela maior parte destes estudantes-atletas vem do tipo de relação que travavam na vida escolar antes da entrada no esporte. Não é surpresa que o sucesso no turfe os leve a priorizar o esporte em detrimento de uma escola que muitos estão matriculados para cumprir uma exigência legal imposta pelo clube. Além disso, a trajetória desses atletas na escola também tem relação com a sua origem social e o capital cultural de suas respectivas famílias conforme pudemos constatar na Tabela 2.

\section{Família e desempenho escolar}

No que diz respeito à escolarização dos pais, observamos que a maioria deles interrompeu os estudos nas $5^{\mathrm{a}}$ e $8^{\mathrm{a}}$ séries, atualmente nomeados de $6^{\circ}$ e $9^{\mathbf{o}}$ anos, respectivamente. Um estudante-atleta relatou que não sabia em que série seu pai havia deixado a escola. Isso sugere que este tema pode não ter importância no seu convívio familiar, ou que o pai possui baixa escolaridade. Em relação às mães, os resultados mostram uma maior concentração de conclusão dos estudos na $3^{\mathrm{a}}$ série do ensino médio.

Se retomarmos a ideia do desinteresse intrínseco no sistema educacional, o conceito de projeto individual (Velho 1997, 2003, 2010) e o dos herdeiros da educação (Bourdieu e Passeron, 2014), teremos um ponto relevante para discutir a trajetória escolar dos estudantesatletas e as escolhas que exercem para investir tempo e dedicação, priorizando o esporte em detrimento da formação na escola. As narrativas dos jovens aprendizes de jóquei sobre a defasagem escolar não se explicam apenas pela repetência. Dos jovens que entrevistamos, cinco responderam que já haviam interrompido os estudos, sendo que quatro deles deram como resposta a mesma causa: a dedicação à carreira esportiva. Entendemos que a declaração de interrupção do estudo motivada pela carreira no esporte pode ter sido um tipo de acordo de fala no contexto da entrevista.

Devemos considerar, também, a influência dos dados socioeconômicos e de origem familiar na trajetória escolar dos atletas em questão. A baixa escolaridade dos responsáveis pode ser fator que explique o fato dos estudantes-atletas não vislumbrarem na escolarização uma possibilidade de mobilidade social e econômica. Outro ponto, dizem os autores Paixão (2005) e Barbosa e Sant'Anna (2010) que as famílias de classes populares tendem relacionar o diploma a uma ocupação no mercado de trabalho. Assim, sugerimos que, no caso estudado, a possibilidade de geração de recursos financeiros ainda no processo de formação esportiva possa ser um fator que interfira na equação que o sujeito pode realizar entre os investimentos no esporte e na escola.

Observemos que um conjunto de fatores podem exercer influência no modo como os estudantes-atletas entendem o projeto educacional. Primeiro, a influência direta dos seus 
responsáveis aponta para uma espécie de herança educacional de pouco prestígio, possivelmente influenciando o modo como os próprios estudantes-atletas vão se relacionar com a escola (Bourdieu, Passeron, 2014). No outro lado, o turfe com possibilidade de ganhos financeiros imediatos. Para um jovem, cuja família apresenta poucos recursos de manutenção e baixa escolaridade, a oportunidade no esporte parece exercer forte influência nas suas escolhas e no projeto de vida. (Velho, 1997, 2003, 2010).

\section{Mercado esportivo versus escolaridade dos estudantes-atletas}

Conforme já indicamos, o mercado esportivo do turfe oferece aos estudantes-atletas uma premiação financeira atraente nessa fase da vida. De acordo com suas conquistas nas corridas, os valores acumulados no ano podem atingir algo inimaginável tanto para a idade quanto para origem social desses estudantes-atletas. Os tutores da formação na escola de jóquei administram os ganhos obtidos pelos atletas. Os ganhos são distribuídos em duas contas bancárias do tipo poupança: uma que o jovem tem acesso para seus gastos ordinários e outra na qual é guardada a maior parte do dinheiro recebido por vitória. O dinheiro acumulado na segunda conta só estará disponível quando o atleta for considerado jóquei profissional. A única exceção para o uso desse dinheiro é quando o jovem requisita uma determinada quantia para comprar um bem julgado como necessário por seus tutores (como um computador ou outro recurso importante para sua formação ou para a família). Observemos, como exemplo, a declaração do administrador do clube: "Outro dia, um deles pediu para comprar uma geladeira, porque a família não tinha. Aí a gente libera.” (Rocha, 2013).

Depreende-se, portanto, que o turfe pode se tornar o principal objetivo do projeto de vida para esses estudantes-atletas — em geral oriundos das classes localizadas na base da estratificação social — em virtude da possibilidade de ganhos financeiros imediatos.

\section{Discussão}

A gestão do tempo é um fator importante para compreendermos a dedicação do estudante-atleta em condição de dupla carreira esportiva (Melo et al., 2016; Melo, Soares, Rocha, 2014; Rocha et al., 2021). Vimos que os estudantes-atletas investigados dispensam muito tempo aos treinamentos e tendem a competir às sextas-feiras, sábados, domingos e segundas-feiras. Esse dado é relevante por mostrar que o estudante-atleta de turfe conduz sua rotina de acordo com as demandas do esporte e tem o tempo dedicado à escola reduzido a três dias na semana. Isso evidencia a existência de um conflito na formatação da dupla carreira nessa modalidade esportiva. Portanto, pode-se sugerir que haja uma desarticulação entre projetos escolares e profissionais para o estudante-atleta de turfe; e que esse processo depende de uma melhor integração das instituições de formação esportiva e escolar (Blodgett; Schinke, 2015; Chroni; Diakaki; Papaioannou, 2013; Metsä-Tokila, 2002; Tshube; Feltz, 2015; Guidotti; Cortis; Capranica, 2015). 
Tomando como referência as pesquisas internacionais, percebe-se que os clubes e as escolas tendem a apresentar uma conduta firmada apenas no cumprimento de normas e, como a legislação brasileira é lacunar quanto à harmonização entre o direito à educação e a profissionalização no esporte, escolas e clubes não formulam políticas que visem a compensar os possíveis prejuízos educacionais dos estudantes-atletas. Portanto, ainda que haja a obrigatoriedade da matrícula, prevista na Lei de Diretrizes e Bases da Educação Nacional (Brasil, 1996), não se faz qualquer exigência às instituições para que o estudanteatleta seja observado como um caso especial no sistema educacional. Desse modo, os clubes garantem que os estudantes-atletas estejam matriculados na escola, mas nem sempre acompanham ou fornecem o suporte necessário para o seu desenvolvimento acadêmico.

O reconhecimento de que o estudante-atleta é um sujeito atípico no sistema educacional brasileiro aparece na justificativa de dois Projetos de Lei (PL) originados no Senado Federal, a saber: o PL nº 2.493/2019 e o PL nº. 4.393/2019 (Brasil, 2019a, 2019b). Ambos consideram a condição diferenciada do estudante-atleta e buscam estratégias para que minimizem os possíveis prejuízos que esses possam vir a ter nas formações esportivas e educacionais. Todavia, se compararmos os dispositivos de cada PL com os conceitos e recomendações das pesquisas sobre dupla carreira, podemos observar que os PL carecem de debate público para tratar do tema e que seus artigos ainda são insuficientes para resolver as demandas de conciliação das rotinas de dupla carreira nas variadas formas de inserção e formação para o esporte profissional (Rocha et al., 2020; Rocha, Pinto, Soares, 2021).

No tocante à pesquisa, verifica-se, com base nos dados analisados, que não há qualquer tipo de política institucional — seja do clube, seja da escola - que tenha como meta a compensação dos prejuízos acadêmicos ocasionados pelas competições esportivas. Torna-se imperativo, portanto, que as instituições planejem e criem condições para a permanência e desenvolvimento desses estudantes-atletas na escola até o fim da educação básica. Tal obrigação é prioritariamente dever da família, do Estado e da sociedade civil (Brasil, 1943, 1990). Esse dispositivo de solidariedade entre a sociedade civil, as famílias e o Estado é mecanismo previsto na Constituição (CF/88, Brasil, 1988) para que se garantam os direitos nela apresentados.

A condição do estudante-atleta como um potencial trabalhador do esporte reforça a ausência de sua figura jurídica na legislação brasileira, o que pode colocar o atleta nessa faixa etária em situação de vulnerabilidade (Rocha, 2017). Nesse caso, a ausência de legislação e a insuficiência dos PL debatida nos textos de Rocha et al. (2020) e Rocha, Pinto e Soares (2021) fazem com que os efeitos da dupla carreira sobre a condição escolar do estudanteatleta estejam vinculados ao tipo de negociação possível para esse fenômeno. Na ausência de norma jurídica, é de responsabilidade da família e dos agentes da educação e do esporte a elaboração de estratégias para minimizar os prováveis prejuízos educacionais de um investimento desequilibrado e focado no ofício esportivo dentro do contexto da dupla carreira.

No que diz respeito ao Tempo de Permanência na Escola do estudante-atleta de turfe, vimos que há uma perda substancial na quantidade de horas de permanência na escola em relação às horas declaradas de treinamento. Se compararmos o Tempo de Permanência na 
Escola dos atletas de turfe ( 2 horas, 17 minutos e 11 segundos) com a média do Tempo de Permanência na Escola dos alunos regulares no Rio de Janeiro ${ }^{9}$ ( 4 horas e 5 minutos), o indicador aponta uma perda de quase 2 horas de ensino formal para esses atletas (Neri, 2009b). Neri (2009b) apontou que o indicador que exerce maior influência na proficiência dos alunos em alguns testes é o Índice de Jornada Escolar.

Notou-se que a redução do Tempo de Permanência na Escola do atleta de turfe está intrinsecamente relacionada à sua frequência escolar. Tendo em vista que as competições levam os atletas a contabilizarem duas faltas semanais, o índice de presença escolar atinge apenas $60 \%$ do volume de aulas. Tal índice vai de encontro ao que é regulamentado pela Lei de Diretrizes e Bases da Educação Nacional (LDB — Lei n ${ }^{\circ}$ 9.394, de 20 de dezembro de 1996), pois, de acordo com o seu art. 24, a carga horária mínima exigida é de 800 horas, distribuídas em pelo menos 200 dias letivos; e "o controle de frequência fica a cargo da escola, conforme o disposto no seu regimento e nas normas do respectivo sistema de ensino, exigida a frequência mínima de setenta e cinco por cento do total de horas letivas para aprovação" (Brasil, 1996, p. 10). O pouco tempo de dedicação às atividades escolares, além de possivelmente acarretar o baixo rendimento nas provas de proficiência (Neri, 2009b), pode fazer com que esses atletas tenham dificuldade em conseguir alguma colocação valorizada no mercado de trabalho na transição pós-carreira esportiva (Christensen; Sørensen, 2009; Metsä-Tokila, 2002; Souza et al., 2008).

Ainda que a frequência escolar seja fator determinante para a redução do tempo de permanência na escola dos estudantes-atletas do turfe, essa causa não é semelhante para a redução do TPE de atletas de outras modalidades esportivas. A literatura que trata do tema com estudantes-atletas de futebol, destaca que a redução do TPE para esses ocorre, provavelmente, por uma falta de estrutura e mecanismos compensatórios na escola (Rocha et al., 2021). Dessa forma, podemos indicar que a falta de padrão nas demandas dos estudantes-atletas de diferentes esportes pode ser fator dificultador na formulação de políticas públicas com vistas à mediação dessas questões.

Observemos que os estudantes-atletas do turfe estudavam no período da noite, assim, podemos sugerir que os efeitos da desestrutura escolar no ensino noturno (Rocha et al., 2021; Leão, 2018; Costa, 2011), bem como o tipo de calendário desse esporte que pode suprimir até dois dias de frequência à escola, afetam ainda mais o TPE para os estudantes-atletas que investigamos. Se esses estudantes-atletas já chegam ao turfe com trajetórias escolares acidentadas, a baixa frequência à escola poderá afetar ainda mais a formação escolar desses atletas do turfe. De fato, a estrutura desse esporte e as formas de conciliação que travam com a escola coloca esses estudantes-atletas em situação de vulnerabilidade no sistema educacional. Isso é mais um elemento que contribui para estes atletas se dedicarem de forma quase que exclusiva ao projeto esportivo em detrimento do projeto de escolarização.

Considerando o debate internacional, as recomendações para o desenvolvimento de um programa que busque a harmonização das rotinas da dupla carreira envolvem comissões institucionais especializadas no trato e na formulação de estratégias para atendimento dos estudantes-atletas de forma quase individualizada. Assim, pesquisas demonstram que políticas dessa natureza permitem a conciliação da dupla carreira mais satisfatoriamente 
(Lopes de Subijana e Equiza Vaquero, 2018). Os estudante-atletas atendidos por programas de conciliação da dupla-carreira em instituições especializadas e/ou com serviços individualizados (tutoria para formação escolar e esportiva) tendem a ter transições menos acidentadas tanto no esporte quanto na escolarização e, posteriormente, esse processo formativo permite a inserção no mercado de trabalho após a carreira esportiva sem grandes percalços (Lopes de Subijana e Equiza Vaquero, 2018).

As experiências internacionais podem nos inspirar para pensar modelos e estratégias para a conciliação da dupla carreira no cenário nacional. Ainda que a situação brasileira possa demonstrar incompatibilidades no sistema educacional que, aparentemente, não se faz presente nos modelos internacionais, vislumbra-se que o planejamento e gestão da dupla carreira do estudante-atleta deve ser feito em regime de solidariedade entre as instituições envolvidas na vida do jovem atleta - família, esporte e escola (Rocha, Pinto, Soares, 2021).

Guidotti, Cortis e Capranica (2015) realizaram uma profunda revisão da literatura relacionada ao tema da dupla carreira no esporte e na escola. As autoras identificaram que os textos referentes a essa temática, em geral, sugerem que a dupla carreira de estudantes-atletas só é conciliada com sucesso quando há medidas que flexibilizam o currículo escolar sem causar prejuízos na formação. Além disso, as autoras indicaram a necessidade do investimento em pesquisas que considerem também as motivações que levam os estudantesatletas a optarem pela dupla carreira, compreendendo a relação de dependência entre escola e esporte.

No Brasil, o debate sobre a conciliação entre a escola e a formação de atletas de alto rendimento é pouco desenvolvido nas agendas das federações esportivas, das políticas governamentais e dos sistemas de ensino. O que há são iniciativas isoladas de clubes ou instituições formadoras, que estabelecem convênios com escolas privadas ou possuem escolas com regime especial para seus atletas. Atualmente, há dois projetos de Lei em tramitação no Congresso Nacional (Brasil, 2019a, 2019b). O primeiro prevê a reserva de vagas no sistema de educação federal para estudantes-atletas; o segundo, propõem o regime domiciliar ou à distância para os atletas que se ausentarem das atividades escolares em função das atividades que exercem. Todavia, ambos os projetos carecem de discussão aprofundada e reconhecimento das condições da dupla carreira do atleta de alto rendimento no Brasil. Os projetos de Lei, mesmo com justificativas interessantes, operacionalizam seus artigos e normas prescritivas de maneira ora contraditória, ora insuficiente para buscar a harmonia nas rotinas do estudante-atleta (Rocha et al., 2020; Rocha, Pinto, Soares, 2021)

$\mathrm{O}$ afrouxamento das normas regulares da escola para melhor conciliar as demandas da dupla carreira também foi apresentado nas pesquisas de Melo et al. (2016), Soares et al. (2013), Melo, Soares e Rocha (2014) e Da Conceição (2015). Esses autores indicaram que os estudantes-atletas investigados buscavam negociações junto às escolas, professores e gestores para obterem privilégios ou possibilidades de conciliação da escola com as demandas esportivas. Esses privilégios eram, geralmente, relacionados a abonos de faltas, remarcação de provas e flexibilização dos horários de entrada e saída nas obrigações escolares. Essas estratégias evidenciam os efeitos da ausência de regulamentação da dupla carreira e não vão na direção de suprir as necessidades de formação do estudante-atleta. 
As pesquisas nacionais relatam que a flexibilização das normas regulares da escola para os estudantes-atletas em dupla carreira está sujeita a decisões discricionárias dos responsáveis escolares, portanto, tais negociações não estão ancoradas em programas institucionais, como ocorre em parte da Europa. Além disso, é mencionado que os estudantes-atletas citados nessas pesquisas, quando não conseguiam obter concessões quanto às normas e tarefas mediante negociações com os gestores da escola, comumente migravam para outra instituição de ensino ou turno escolar a fỉm de conseguirem melhorar a compatibilização das rotinas de dupla carreira, mesmo gerando prejuízo na formação acadêmica (Melo, 2010).

Salientamos, ainda, que o Tempo de Permanência na Escola não é o único fator que determina o sucesso ou fracasso escolar dos alunos, mas, com certeza, exerce um impacto negativo no rendimento, como apontado pela literatura (Neri, 2009a, 2009b). Mas sabemos também que outros fatores são determinantes para pensarmos como as desigualdades de oportunidades educacionais se manifestam: como a estrutura familiar, o nível socioeconômico, as desigualdades urbanas, entre outros fatores (Soares, Almeida, 2019; Paulilo, 2017; Koslinski, Alves, Lange, 2013). Portanto, ao analisarmos os dados sobre os estudantes-atletas do turfe, sabemos que a trajetória acidentada no sistema educacional é anterior a entrada deles na modalidade esportiva. Dessa forma, sugerimos que, como mostra a tradição das pesquisas sobre trajetória escolar, as características de origem explicariam melhor o fracasso escolar deles que propriamente o esporte. Noutra direção, observamos que o calendário de competições afeta o TPE e isso talvez não permita uma mudança de percepção desses atletas em relação a carreira escolar e os possíveis ganhos que possam obter através desse tipo de formação. A condição de atleta em formação profissional no turfe sugere que o tipo de harmonização das carreiras pode exercer influência negativa na escolarização dos estudantes-atletas dessa modalidade.

Verificamos, também, que os estudantes-atletas atribuem maior importância à carreira esportiva do que à escola. Podemos sugerir que os ganhos imediatos proporcionados pela profissionalização precoce no turfe sejam o grande atrativo para jovens oriundos dos estratos mais inferiores da pirâmide social, além do sucesso no turfe subjetivamente experimentado quando comparado com a escola. Costa e Koslinski (2006), em estudo das percepções sobre a aposta na carreira, realizado com estudantes de escolas públicas de alto e baixo prestígio do Rio de Janeiro, observaram que os alunos das escolas de baixo prestígio tendem a criar expectativas de seguir uma carreira que independa da formação acadêmica. Os dados sugerem que essa interpretação pareça ser adequada também aos atletas de turfe.

Nogueira e Nogueira (2002) destacaram que, para as famílias das classes populares, a aposta em uma carreira que depende da progressão na escola seria um investimento em longo prazo e com poucas oportunidades de sucesso. Portanto, o investimento nos estudos somente se justificaria se os resultados escolares desses jovens fossem extremamente positivos nos primeiros anos de escola, de modo que "essas famílias tenderiam, assim, a privilegiar as carreiras escolares mais curtas, que dão acesso mais rapidamente à inserção profissional" (Nogueira, Nogueira, 2002, p. 24). Nogueira e Nogueira (2002) destacaram, ainda, que a compreensão por parte da família sobre as estruturas inerentes à escola - no que concerne 
ao prestígio social, qualidade acadêmica e retorno financeiro - provavelmente colaboraria para redefinir a trajetória de seus filhos.

Podemos inferir, portanto, que os jovens priorizam a profissionalização no esporte em razão da conjunção de fatores que afastam as camadas populares da escola. No mesmo sentido, Rial (2006) e Souza et al. (2008) apontam que o ingresso e a permanência na carreira esportiva consistem em um projeto que depende do apoio familiar e da dedicação incondicional que o esporte exige.

\section{Conclusão}

A pesquisa revelou que há uma difícil conciliação entre a formação profissional no esporte de alto rendimento e a escolarização dos atletas do turfe. A dedicação à escola básica é vista como uma questão secundária, confirmando a hipótese de que o tempo dispensado à rotina de treinamento pode concorrer com o empenho exigido para uma boa formação na escola básica. Paradoxalmente, para a seleção e manutenção dos atletas no clube, exige-se que permaneçam matriculados no ensino básico, ainda que a frequência e a dedicação à escola sejam precárias. Ademais, observamos que a origem social desses jovens pode justificar a insuficiência no investimento escolar em comparação com o esporte.

O que agrava a conciliação entre escolarização e esporte, no caso específico desses atletas, é a baixa frequência escolar devido à concomitância entre competições e atividades escolares. As pesquisas em educação sugerem que o pouco tempo de permanência e a baixa dedicação aos bancos escolares prejudicam o rendimento dos estudantes nos testes de proficiência. No caso de insucesso na carreira esportiva, o estudante-atleta encontraria limitadas possibilidades de ocupação de um cargo profissional no mercado de trabalho após a carreira esportiva.

Nossos dados sugerem, ainda, que a rotina de treinamento e as competições remuneradas colocam a escola em posição de menor relevância. Somado a essa percepção está o fato de que o índice de repetência entre os estudantes-atletas é elevado, gerando uma defasagem na relação idade ideal/ano escolar; apesar disso, a entrada no turfe possibilitou, de uma forma ou de outra, o retorno à escola de alguns desses atletas que haviam abandonado os estudos. Todavia, a maior dedicação aos compromissos exigidos pelo esporte os leva a adotar — em acordo com a escola, dirigentes e família - medidas que visam flexibilizar normas escolares. No entanto, necessitamos de estudos mais controlados para avaliar com maior profundidade o efeito desses mecanismos na educação institucionalizada desses jovens no turfe e em outros esportes.

O Brasil atribui ao esporte um significado de instituição formadora e redentora da juventude. Talvez isso ajude a explicar o contingente juvenil que busca a mobilidade social e econômica por meio da carreira esportiva, haja vista ser quase independente da formação escolar. Entretanto, questionamos: como um país que atribui tamanha importância ao esporte não oferece nenhum tipo de política educacional que tenha como foco mediar a relação entre a profissionalização no esporte e a escolarização? A falta de uma política pública ou de 
programas especiais para essa população de estudantes-atletas acaba por permitir que essas agências de formação (esporte e escola) construam acordos que podem ferir a legislação ou os futuros interesses dos jovens que buscam a profissionalização no esporte.

Por fim, vale apontar que as pesquisas em educação e educação física no Brasil abordam escassamente esse tema, o que nos leva a sugerir a necessidade de ampliação desse campo de discussão e sistematização de dados para fomentar a criação de políticas públicas ou programas que preencham essa lacuna no sistema educacional. Tais políticas devem permitir que os jovens conciliem estudos e profissionalização esportiva, contemplando também o contingente de jovens que não obterá sucesso no esporte profissional. No caso do turfe, o atleta pode vencer numerosos páreos durante a formação e a carreira esportiva, contudo, se precisar competir no mercado de trabalho mais amplo, provavelmente entrará nessa disputa em desvantagem.

\section{Notas:}

1. Esta pesquisa contou com apoio e financiamento da CAPES, através da bolsa concedida ao primeiro autor; e das agências de fomento CNPq; e FAPERJ.

2. O turfe é um esporte de corrida de cavalos.

3. O tempo de permanência na escola é uma referência à pesquisa de Marcelo Neri (2009b), na qual o autor faz uso de índices relacionados a matrícula e frequência dos alunos, além de considerar a jornada escolar para calcular o tempo efetivo em que os alunos permanecem estudando.

4. As dependências para atletas ficam localizado no bairro da Gávea, na zona sul da cidade do Rio de Janeiro no Jóquei Clube.

5. Ver o site https://site.jcb.com.br/conteudo/Modal_Estatisticas_Joqueis.aspx, acesso em 18 jun. 2021.

6. Há representações no Congresso Nacional que visam adequar a rotina do atleta em formação, conciliandoa com a sua formação educativa. Tratam-se dos Projetos de Lei (PL) nº 4.393/2019 e do PL nº 2.493/2019 (Brasil, 2019a, 2019b).

7. Nesse tempo de treino, não está incluído o tempo dedicado às tarefas de manutenção e limpeza do estábulo e do alojamento. Além disso, não consideramos o tempo que os jovens dedicam aos treinamentos físicos, administrados individualmente, assim como o período de competição para os que já são aprendizes. Tais variáveis ampliariam, consideravelmente, o tempo de trabalho dos jovens aprendizes de jóquei.

8. Assim como Neri (2009b), adotamos como Jornada de Referência um período de 5 horas diárias. Sendo assim, verificamos que a jornada escolar dos jovens atletas representa, aproximadamente, $76 \%$ da Jornada de Referência.

9. Ver Neri (2009b).

\section{Referências}

ABEP - Associação Brasileira de Empresas de Pesquisa. Alterações na Aplicação do Critério Brasil, válidas a partir de 01/06/2019. 2019. Disponível em: < http://www.abep.org/criterio-brasil.>. Acesso em: 18 jun. 2021. 
BARBOSA, M. L. de O.; SANT'ANNA, M. J. G. As classes populares e a valorização da educação no Brasil. IN: RIBEIRO, L. C. de Q. et al. (Orgs). Desigualdades urbanas, desigualdades escolares. Rio de Janeiro: Letra Capital - Observatório das Metrópoles - IPPUR/UFRJ, 2010, p. 155-174.

BLODGETT, A. T.; SCHINKE, R. J. "When you're coming from the reserve you're not supposed to make it": Stories of Aboriginal athletes pursuing sport and academic careers in "mainstream" cultural contexts. Psychology of Sport and Exercise, v. 21, p. 115-124. 2015.

BOURDIEU, P; PASSERON, J. C. Os herdeiros, os estudantes e a cultura. Florianópolis-SC, Editora UFSC, 2014.

BRASIL. Projeto de Lei $\mathbf{n}^{\mathbf{0}}$ 2.493, de 24 de abril de 2019. Altera a Lei $\mathrm{n}^{\mathbf{0}}$ 9.394, de 20 de dezembro de 1996, que estabelece as diretrizes e bases da educação nacional, e altera a Lei no 12.711 , de 29 de agosto de 2012 , que dispõe sobre o ingresso nas universidades federais e nas instituições federais de ensino técnico de nível médio e dá outras providências. Brasília: Senado Federal, 2019a. Disponível em: <https://www25.senado.leg.br/web/atividade/materias/-/materia/136475>. Acesso em: 02 abr. 2020.

BRASIL. Projeto de lei $\mathbf{n}^{\mathbf{0}}$ 4.393, de 13 de agosto de 2019. Que dispõe sobre a assistência, em regime de exercícios domiciliares ou à distância, para estudantes da Educação Básica que participem periodicamente de competições desportivas e paradesportivas ou exerçam atividades artísticas itinerantes. Brasília: Senado Federal, 2019b. Disponível em: https://www25.senado.leg.br/web/atividade/materias/-/materia/138079. Acesso em: 02 abr. 2020.

BRASIL. Lei $\mathbf{n}^{\circ}$ 9.394, de 20 de dezembro de 1996. Estabelece as diretrizes e bases da educação nacional. Brasília, 1996. Disponível em: 〈http://portal.mec.gov.br/arquivos/pdf/ldb.pdf〉. Acesso em: 15 out. 2010.

BRASIL. Lei no 8.069, de 13 de julho de 1990. Dispõe sobre o Estatuto da Criança e do Adolescente e dá outras providências. Disponível em: <http://www.planalto.gov.br/ccivil_03/leis/18069.htm>. Acesso em: 04 ago. 2011.

BRASIL. Constituição da República Federativa do Brasil de 1988. Brasília, DF, Brasil, 1988. Disponível em: <http://www.planalto.gov.br/ccivil_03/constituicao/constituicao.htm.>. Acesso em: 18 jun. 2021.

BRASIL. Decreto-lei $\mathbf{n}^{\mathbf{0}} \mathbf{5 . 4 5 2}$, de $\mathbf{1}^{\circ}$ de maio de 1943. Aprova a Consolidação das Leis do Trabalho. Disponível em: <http://www.planalto.gov.br/ccivil_03/decreto-lei/del5452.htm>. Acesso em: 03 ago. 2019.

CHRISTENSEN, M. K.; SØRENSEN, J. K. Sport or school? Dreams and dilemmas for talented young Danish football players. European Physical Education Review, v. 15, n. 1, p. 115-137, nov. 2009.

CHRONI, S. 'ANI'; DIAKAKI, E.; PAPAIOANNOU, A. Athletes' careers in Greece: Towards a culturally infused future. In: STAMBULOVA, N. B.; RYBA, T. V. (Eds.). Athletes' careers across cultures. New York: Taylor \& Francis Group, 2013. E-book.

CORREIA, C. A. J. Entre a Profissionalização e a Escolarização: Projetos e Campo de Possibilidades em jovens atletas do Colégio Vasco da Gama. 2014. Dissertação (Mestrado em Educação) — Universidade Federal do Rio de Janeiro, Rio de Janeiro. Disponível em: <http://www.educacao.ufrj.br/dcarlusaugustus.pdf>. Acesso em: 07 out. 2016.

COSTA, F. R. da. A escola, o esporte e a concorrência entre estes mercados para jovens atletas mulheres no futsal de Santa Catarina. 2012. Tese (Doutorado em Educação Física) - Programa de Pós-graduação em Educação Física, Universidade Gama Filho, Rio de Janeiro, 2012.

COSTA, A. L. J. da. As escolas noturnas do município da Corte: estado imperial, sociedade civil e educação do povo (1870-1889). Educ. Soc., Campinas, v. 32, n. 114, p. 53-68, mar. 2011. Disponível em: <https://www.scielo.br/scielo.php?pid=S0101-

73302011000100004\&script=sci_abstract\&tlng=pt\#: :text=Luiza\%20Jesus\%20da.-

,As\%20escolas\%20noturnas\%20do\%20munic\%C3\%ADpio\%20da\%20Corte $\% 3$ A $\% 20$ estado\%20imperial $\% 2 \mathrm{C} \% 20$ sociedade,Educ.\&text=Este $\% 20$ trabalho\%20exp $\% \mathrm{C} 3 \% \mathrm{~B} 5 \mathrm{e} \% 20$ parte $\% 20 \mathrm{dos}$,experi\%C3\%AAnc ia\%20de\%20educa\%C3\%A7\%C3\%A3o\%20do\%20povo>. Acesso em: 30 maio 2018. 
COSTA E SILVA, A. L. da. Esporte e Escolarização: projetos, biografias e programa governamental. 2016. Dissertação (Mestrado em Educação Física) - Universidade Federal do Espírito Santo, Vitória-ES.

COSTA, M. da; KOSLINSKI, M. C. Entre o mérito e a sorte: escola, presente e futuro na visão de estudantes do ensino fundamental do Rio de Janeiro. Revista Brasileira de Educação, Rio de Janeiro, v. 11, n. 31, p. 133-211. $2006 . \quad$ Disponível em: <http://www.scielo.br/scielo.php?script=sci_arttext\&pid=S141324782006000100010\&lng=en\&nrm=iso>. Acesso em: 22 abr. 2010.

DA CONCEIÇÃO, D. M. O estudante-atleta: desafios de uma conciliação entre a escolarização e a formação esportiva no futebol. Dissertação (mestrado) - Universidade Federal de Santa Catarina, Centro de Ciências da Educação, Programa de Pós-Graduação em Educação, Florianópolis, 2015. Disponível em: < https://repositorio.ufsc.br/xmlui/handle/123456789/158781> Acesso em: 18 jun. 2021.

EPIPHANIO, E. H. Conflitos vivenciados por atletas quanto à manutenção da prática esportiva de alto rendimento. Estudos em Psicologia, Campinas, v. 19, n. 1, jan./abr. 2002. Disponível em: $<$ http://www.scielo.br/scielo.php?script=sci_arttext\&pid=S0103166X2002000100002\&lng=en\&nrm=iso>. Acesso em: 25 ago. 2010.

GUIDOTTI, F.; CORTIS, C.; CAPRANICA, L. Dual Career of European Student-athletes: a systematic literature review. Kinesiologia Slovenica, Ljubljana - Eslovênia, v. 21, n. 3, p. 5 - 20. 2015. Disponível em:

https://www.senato.it/application/xmanager/projects/leg17/attachments/documento_evento_procedura_co mmissione/files/000/003/851/revisione_della_letteratura_sulla_doppia_carriera.pdf $>$. Acesso em: 17 nov. 2016.

JOCKEY CLUB BRASILEIRO. Ranking dos Jóqueis na Gávea. 2021. Disponível em: <https://site.jcb.com.br/conteudo/Modal_Estatisticas_Joqueis.aspx>. Acesso em 18 jun. 2021.

KOSLINSKI, Mariane Campelo; ALVES, Fátima; Lange, Wolfram Johannes. Desigualdades educacionais em contextos urbanos: um estudo da geografia de oportunidades educacionais na cidade do Rio de Janeiro. Educação \& Sociedade [online]. v. 34, n. 125, 2013, pp. 1175-1202. Disponível em: <https://doi.org/10.1590/S0101-73302013000400009>. Acesso: 19 jun. 2021. Epub 06 Mar 2014. ISSN 1678-4626. https://doi.org/10.1590/S0101-73302013000400009.

KRAWCZYK, N. Reflexão sobre alguns desafios do ensino médio no Brasil hoje. Cad. Pesqui., São Paulo, v. 41, n. 144, p. 752-769, Dec. $2011 . \quad$ Disponível em: $<$ http://www.scielo.br/scielo.php?script=sci_arttext\&pid=S0100-

15742011000300006\&lng=en\&nrm=iso>. Acesso em: 08 Jan. 2021. https://doi.org/10.1590/S010015742011000300006.

LEAO, G. O que os jovens podem esperar da reforma do ensino médio brasileiro? Educ. rev., Belo Horizonte, v. 34, e177494, 2018. Disponível em: <http://www.scielo.br/scielo.php?script=sci_arttext\&pid=S010246982018000100126\&lng=en\&nrm=iso>. Acesso em: 08 Jan. 2021. Epub Mar 05, 2018. https://doi.org/10.1590/0102-4698177494.

METSÄ-TOKILA, T. Combining competitive sports and education: how top-level sport became part of the school system in the Soviet Union, Sweden and Finland. European Physical Education Review, v. 8, n. 3, p. 196-206. 2002.

MELO, V. A. de. Cidade esportiva: primórdios do esporte no Rio de Janeiro. Rio de Janeiro: Relume-Dumará:, 2001.

MELO, L. B. S. Formação e escolarização de jogadores de futebol do Estado do Rio de Janeiro. 2010. Dissertação (Mestrado em Educação Física) - Universidade Gama Filho, Rio de Janeiro.

MELO, L. B. S. de; SOARES, A. J. G.; ROCHA, H. P. A. da. Perfil educacional de atletas em formação no futebol no Estado do Rio de Janeiro. Rev. bras. educ. fís. esporte, São Paulo, v. 28, n. 4, p. 617-628, dez. 2014. 
$<$ http://www.scielo.br/scielo.php?script=sci_arttext\&pid=S180755092014000400617\&lng=pt\&nrm=iso>. Acesso em: 07 out. 2016.

MELO L. B. S., et al. Jornada escolar versus tempo de treinamento: a profissionalização no futebol e a formação na escola básica. Rev. Bras. Ciênc. Esporte. 2016. Disponível em: <http://dx.doi.org/10.1016/j.rbce.2015.11.003>. Acesso em: 07 out. 2016.

NERI, M. C. O paradoxo da evasão e as motivações dos sem escola. In: VELOSO, F. et al. (Orgs.). Educação básica no Brasil: construindo o país do futuro. Rio de Janeiro: Elsevier, p. 25-50. 2009a.

NERI, M. C. (Coord.). Tempo de Permanência na Escola. Rio de Janeiro: FVG/IBRE, CPS, 2009b. Disponível em: <http://www.fgv.br/cps/tpe/>. Acesso em: 10 jun. 2011.

NOGUEIRA, C. M. M.; NOGUEIRA, M. A. A sociologia da educação de Pierre Bourdieu: limites e contribuições. Educ. Soc., Campinas, v. 23, n. 78, abr. 2002. Disponível em $<$ http://www.scielo.br/scielo.php?script=sci_arttext\&pid=S0101-3302002000200003\&lng=pt\&nrm=iso>. Acesso em: 26 jun. 2011.

PAIXÃO, L. P. Significado da escolarização para um grupo de catadoras de um lixão. Cadernos de Pesquisa, v. $35, \quad$ n. 124, jan./abr. 2005, p. 141-170. Disponível em: < https://www.scielo.br/j/cp/a/CRkfsxFrZgbb3bCDKdfstJh/?lang=pt $>$. Acesso em: 14 jan. 2013.

PAOLI, P. B. Os estilos de futebol e os processos de seleção e detecção de talentos. 2007. Tese (Doutorado em Educação Física) — Universidade Gama Filho, Rio de Janeiro.

PAULILO, A. L. A compreensão histórica do fracasso escolar no Brasil. Cadernos de Pesquisa [online]. v. 47, n. 166, 2017, pp. 1252-1267. Disponível em: 〈https://doi.org/10.1590/198053144445>. Acesso 19 jun. 2021. ISSN 1980-5314. https://doi.org/10.1590/198053144445.

RIAL, C. S. Futebolistas brasileiros na Espanha: emigrantes porém... Revista de Dialectología y Tradiciones Populares, v. LXI, n. 2, p. 163-190. 2006. Disponível em: <http://rdtp.revistas.csic.es/index.php/rdtp/article/view/20/20>. Acesso em: 28 abr. 2010.

ROCHA, H. P. A. da. A escola dos jóqueis: a escolha da carreira do aluno atleta. 2013. Dissertação (Mestrado em Educação) - Programa de Pós-graduação em Educação, Universidade Federal do Rio de Janeiro, Rio de Janeiro, 2013. Disponível em: <http://labec-ufrj.com/dissertacoes/disserhugopaula.pdf >. Acesso em: 04 jul. 2013.

ROCHA, H. P. A. da. O futebol como carreira, a escola como opção: o dilema do jovem atleta em formação. 2017. Tese (Doutorado em Educação) - Programa de Pós-Graduação em Educação, Universidade Federal do Rio de Janeiro, Rio de Janeiro, 2017. Disponível em: <http://www.educacao.ufrj.br/ppge/teses2017/tHugoAlmeida.pdf>. Acesso em: 30 maio 2018.

ROCHA, H. P. A. da et al. Jovens Esportistas: profissionalização no futebol e a formação na escola. Motriz: Revista de Educação Física (Online), v. 17, p. 252-263, 2011. Disponível em: <https://www.scielo.br/j/motriz/a/rp7hv5GRKwffLfSSX7DphGg/?lang=pt\&format=pdf>. Acesso em: 29 Jun. 2021.

ROCHA, H. P. A. da et al. A dupla carreira esportiva no Brasil: Um panorama na agenda das políticas públicas. Revista Com Censo Estudos Educacionais do Distrito Federal, v. 7, p. 52-59, 2020. Disponível em: < http://periodicos.se.df.gov.br/index.php/comcenso/article/view/848/519>. Acesso em: 29 jun. 2021.

ROCHA, H. P. A. da et al. Educação e esporte: analisando o tempo escolar do estudante-atleta de futebol. Educação em Revista [online]. 2021, v. 37, e20719. Disponível em: <https://doi.org/10.1590/0102469820719>. Acesso em: 29 Jun. 2021. Epub 19 Abr. 2021. ISSN 1982-6621. https://doi.org/10.1590/0102469820719.

ROCHA, H. P. A. da; PINTO, E. A.; SOARES, A. J. G. Marco Legal da dupla carreira: perspectivas e limites do Projeto de Lei no. 4.393/2019. Revista da Alesde, v. 13, p. 39-53, 2021. Disponível em: < https://revistas.ufpr.br/alesde/article/view/76097/43765>. Acesso em: 29 jun. 2021. 
ROMÃO, M. G. Família e projeto: um estudo a partir do Programa Bolsa Atleta Estudantil. 2017. Dissertação (Mestrado em Educação Física) - Universidade Federal do Espírito Santo, Vitória-ES, 2017. Disponível em: <http://www.educacaofisica.ufes.br/pos-graduacao/PPGEF/detalhes-da-tese?id=10571>. Acesso em: 03 abr. 2017.

SOARES, D; ALMEIDA, L. S. Para além da nota: definição de perfis de sucesso e fracasso escolar. Psicologia Escolar e Educacional [online]. v. 23, 2019, e193894. Disponível em: <https://doi.org/10.1590/217535392019013894>. Acesso em: 19 Jun. 2021. Epub 9 Dez 2019. ISSN 2175-3539. https://doi.org/10.1590/2175-35392019013894.

SCHWARTZMAN, S. O viés acadêmico na educação brasileira. Pensamiento Educativo, Revista de Investigación Educacional Latinoamericana (PEL), Santiago de Chile, v. 48, n. 1. 2011. Disponível em: <http://www.schwartzman.org.br/simon/agenda9.pdf>. Acesso em: 01 dez. 2011.

SCHWARTZMAN, S. Educação média profissional no Brasil: situação e caminhos. São Paulo: Fundação Santillana, 2016.

SOARES, A. J. G. et. al. Time for football and school: an analysis of young brazilian players from Rio de Janeiro. Estúdios Sociológicos, v. 31, p. 1-14, 2013.

SOUZA, C. A. M. de et al. Difícil reconversão: futebol, projeto e destino em meninos brasileiros. Horiz. antropol., Porto Alegre, v. 14, n. 30, dez. 2008. Disponível em: $<$ http://www.scielo.br/scielo.php?script=sci_arttext\&pid=S0104-

$71832008000200004 \& \operatorname{lng}=\mathrm{en} \& n r m=i s o>$. Acesso em: 20 dez. 2010.

TSHUBE, T.; FELTZ, D. L. The relationship between dual-career and post-sport career transition among elite athletes in South Africa, Botswana, Namibia and Zimbabwe. Psychology of Sport and Exercise, v. 21, p. 109-114. 2015.

VELHO, G. Individualismo e cultura: notas para uma antropologia da sociedade contemporânea. $2^{\mathrm{a}}$ ed. Rio de Janeiro: Zahar, 1997.

VELHO, G. Projeto e metamorfose: antropologia das sociedades complexas. $3^{\text {a }}$ ed. Rio de Janeiro: Jorge Zahar, 2003.

VELHO, G. A utopia urbana: um estudo de antropologia social. $7^{\mathrm{a}}$ ed. Rio de Janeiro: Zahar, 2010.

\section{Correspondência}

Hugo Paula Almeida da Rocha: Doutor em Educação pela Universidade Federal do Rio de Janeiro (UFRJ). Professor de Educação Física do Colégio Pedro II, Rio de Janeiro-RJ, Brasil. Vice-presidente da Associação Brasileira sobre Dupla Carreira Esportiva (ABDC). Docente no Programa de Mestrado Profissional em Educação Física em Rede Nacional (PROEF). Pesquisador do Laboratório de Pesquisas em Educação do Corpo (LABEC/ UFRJ) e do Grupo de Pesquisa sobre Dupla Carreira Esportiva (FEF$\mathrm{UnB})$.

E-mail: hrocha@cp2.g12.br

Orcid: https://orcid.org/0000-0003-2237-1155

Felipe Rodrigues da Costa: Doutor em Educação Física pela Universidade Gama Filho (UGF). Professor da Faculdade de Educação Física e do Programa de Pós-graduação em Educação Física da Universidade de Brasília (FEF/UnB). Presidente da Associação Brasileira sobre Dupla Carreira Esportiva (ABDC). Pesquisador do Centro de Investigação de Desporto e Atividade Física da Universidade de Coimbra (CIDAF/UC) e coordenador do Grupo de Pesquisa sobre Dupla Carreira Esportiva (DuCa/UnB). 
E-mail: fcostavix@gmail.com

Orcid: https://orcid.org/0000-0002-1817-5058

Antonio Jorge Gonçalves Soares: Professor Titular da Faculdade de Educação e do Programa de Pósgraduação em Educação da Universidade Federal do Rio de Janeiro (UFRJ). Bolsista de Produtividade Pq. 1D (CNPq). Cientista do Nosso Estado da Fundação de Amparo à Pesquisa do Estado do Rio de Janeiro (CNE/FAPERJ). Coordenador do Laboratório de Pesquisas em Educação do Corpo (LABEC/ UFRJ).

E-mail: ajgsoares@gmail.com

Orcid: https://orcid.org/0000-0001-7769-9268

Texto publicado em Currículo sem Fronteiras com autorização dos autores. 